\title{
Influência do Molibdênio em Propriedades do Metal de Solda na Soldagem Molhada com Eletrodos Óxi-Rutílicos
}

\author{
(Influence of Molybdenum in Metal Weld Properties in Welding Wet with Oxy-Rutillic Electrodes)
}

\author{
Luciana Ferreira Silva ${ }^{1}$, Valter Rocha dos Santos ${ }^{1}$, Sidnei Paciornik ${ }^{1}$, Fernando Assunção Rizzo ${ }^{1}$, Mauricio Jesus Monteiro ${ }^{1}$, \\ Alexandre Q. Bracarense ${ }^{2}$ Ezequiel C. Pessoa ${ }^{3}$, Leonardo A. Vieira ${ }^{4}$, R. R. Marinho \\ ${ }^{1}$ PUC-Rio,Departamento de Engenharia de Materiais, Rio de Janeiro, R.J, Brasil, sf.luciana04@gmail.com,valtersa@esp.puc-rio.br, \\ sidnei@puc-rio.br, rizzo@puc-rio.br \\ ${ }^{2} U F M G$, Departamento de Engenharia Mecânica, Belo Horizonte, MG, Brasil \\ ${ }^{3}$ Departamento de Mecânica Industrial, Ouro Preto, MG, Brasil \\ ${ }^{4}$ ESAB, Soldagem e Corte, Contagem, MG, Brasil \\ ${ }^{5}$ PETROBRAS, CENPES, Rio de Janeiro, R.J, Brasil
}

\begin{abstract}
Resumo
A técnica de soldagem subaquática molhada com eletrodos revestidos apresenta um crescente potencial de aplicação para reparos submarinos em elementos estruturais de unidades flutuantes de produção de petróleo (profundidade até 20 m). Porém, ela apresenta problemas tais como o maior risco de fissuração a frio e de formação acentuada de porosidade. O presente trabalho tem como objetivo melhorar a resistência mecânica do metal de solda de um eletrodo experimental do tipo oxi-rutílico. Foram estudadas as influências de adições de Mo (até 0,4\% no metal de solda) na microestrutura e em propriedades mecânicas. As soldas foram realizadas em simulador de soldagem subaquática em profundidade equivalente de $10 \mathrm{~m}$ utilizando um sistema de soldagem por gravidade. As análises das micrografias mostrou que o aumento do teor de Mo no metal de solda diminui significantemente o tamanho médio de grão da região reaquecida de grãos finos. O aumento do teor de Mo no metal de solda resultou, ainda, em aumento do limite de resistência à tração sem perdas de tenacidade e ductilidade até aproximadamente 0,25\% Mo.
\end{abstract}

Palavras-chave: Soldagem subaquática molhada. Eletrodo revestido oxidante. Adição de molibdênio. Propriedades mecânicas.

\begin{abstract}
: the underwater wet welding with coated electrodes technique is undergoing an important use growth in underwater repairs of oil production floating unit's structural elements (up to $20 \mathrm{~m}$ depth). However, it presents problems such as increased risk of cold cracking and sharp porosity formation. This work aims to improve the weld metal's mechanical strength through the addition of molybdenum to experimental oxy-rutilic type electrodes. Both the microstructure and the mechanical properties of weld metals were studied while electrodes would receive additional Mo (up to 0.4\%). The welds were done using a gravity welding system placed in an underwater welding simulator with an equivalent depth of $10 \mathrm{~m}$. Analyses of micrographics shown that the increased level of Mo in weld metal (a) decreases significantly the average grain size of fine-grained reheated region while (b) increases tensile strength limit without loss of toughness and ductility up to 0,25\% Mo approximately.
\end{abstract}

Key-words: Underwater wet welding. Coated oxidizing electrode. Addition of molybdenum. Mechanicals properties.

\section{Introdução:}

A pesquisa e o desenvolvimento em Soldagem Subaquática Molhada (SSM) tende a crescer com o aumento da exploração de petróleo no mar, visando atender às necessidades de reparo de elementos estruturais de plataformas marítimas danificadas devido a fadiga e corrosão, além de estragos acidentais durante e após as instalações. Com isso, a SSM torna-se uma técnica importante e aplicável para a manutenção destas instalações

Recebido em 26/07/2012. Texto final em 23/01/2013. submersas e unidades flutuantes que estão situadas em profundidades de até 20 metros.

A soldagem molhada é um processo bastante complexo, pois é realizada diretamente em contato com o meio aquoso. Devido a este fato surgem problemas que afetam as propriedades mecânicas do metal de solda, tais como, a elevada taxa de resfriamento e a dissociação da água ( $\mathrm{em} \mathrm{H}^{+}$e $\mathrm{O}^{-}$) devido ao calor gerado pelo arco elétrico. A elevada taxa de resfriamento leva a formação de trincas na zona termicamente afetada (ZTA) e no metal de solda, e o oxigênio gerado pela dissociação da água leva à perda dos elementos de liga $(\mathrm{Mn}, \mathrm{Si}, \mathrm{C})$ que são responsáveis pelo ganho de resistência mecânica. $\mathrm{O}$ aumento da profundidade também influencia negativamente no metal de solda, aumentando a porosidade $[1,2]$ e o teor de oxigênio e 
diminuindo o teor de $\mathrm{Mn}$ [3]. A solubilidade do oxigênio no ferro líquido é bastante baixa, em torno de $0.22 \%$ em peso. Portanto o oxigênio medido no metal de solda está quase todo sob a forma de inclusões de óxidos. Isto leva a concluir que também existe um valor constante para a quantidade de inclusões de óxidos em porcentagem volumétrica no metal de solda. São conhecidos os efeitos negativos das inclusões não metálicas nas propriedades mecânicas [4]. O hidrogênio retido no metal de solda (residual) fica aprisionado nas interfaces matriz/inclusões. Por isso, o hidrogênio residual também atinge um valor limite de saturação, em torno de $5 \mathrm{ml} / 100 \mathrm{~g}$, para teores de oxigênio de aproximadamente $0.22 \%$ em peso [5].

Uma solução para estes problemas é o desenvolvimento de um novo tipo de eletrodo revestido oxi-rutílico em que são otimizadas as características dos eletrodos rutílicos e oxidantes. Com isso, elementos de liga que sejam termodinamicamente mais estáveis, perante as condições de soldagem, são adicionados em seus revestimentos com o objetivo de melhorar as propriedades mecânicas do metal de solda e assim possibilitando almejar a qualificação na classe A da norma D3.6M:1990 da AWS [6]. Os eletrodos rutílicos têm um melhor desempenho quanto ao aspecto do cordão e estabilidade do arco [7] e os eletrodos oxidantes são os de maior capacidade de evitar a formação de trincas por hidrogênio na ZTA. Este comportamento deve ser particularmente atribuído ao teor mais baixo de hidrogênio difusível dos depósitos com este eletrodo [8].

Pesquisas realizadas em soldas atmosféricas e molhadas comprovaram que os elementos de liga níquel e molibdênio colaboram fortemente para o aumento das propriedades mecânicas do metal de solda [9]. O motivo de utilizar o níquel como elemento de liga em eletrodos oxidantes se baseia em algumas de suas características. Este elemento é termodinamicamente mais estável em altas temperaturas e, por isso, é facilmente transferido da ponta do eletrodo para a poça de fusão sem sofrer oxidação. Vários trabalhos comprovaram que o níquel exerce uma importante influência sobre as propriedades mecânicas no metal de solda, agindo por solução sólida [10] e também na microestrutura (formação de ferrita acicular), agindo também sobre a diminuição do tamanho de grão [11], resultando

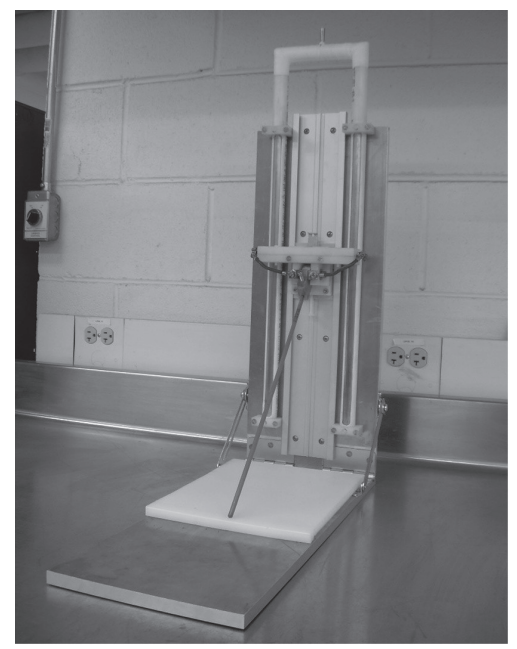

no aumento da resistência mecânica do metal depositado [12].

O molibdênio, assim como o níquel, é um elemento de liga que tem a característica de ser termodinamicamente mais estável que outros elementos em altas temperaturas, sendo possivelmente transportado para poça de fusão sem sofrer oxidação. Além disso, pode contribuir com o aumento das propriedades mecânicas do metal de solda, diminuindo o tamanho de grão [13], aumentando a dureza do metal de solda [14] e contribuindo para o aumento da fração de ferrita acicular $[15,16]$.

Assim, o presente trabalho foi elaborado com o objetivo de avaliar propriedades do metal de solda de cinco eletrodos oxirutilicos, contendo teores de molibdênio (de 0 a $0.4 \%$ ) e de níquel (2\%) adicionados em seus revestimentos. As influências do Mo foram avaliadas por meio de caracterização microestrutural, por microscopia ótica, propriedades mecânicas, por ensaios mecânicos, além da análise química do metal de solda.

\section{Materiais e Métodos:}

\subsection{Materiais:}

Foram utilizados cinco eletrodos oxi-rutílicos (A, B, C, D e E). Estes códigos foram escolhidos para indicar a variação crescente das adições de molibdênio em seus revestimentos. Com estes eletrodos foram soldadas cinco juntas de topo com chanfro $\mathrm{V}$ e, destas juntas, os corpos-de-prova foram retirados para macro e micrografia, ensaio de tração, ensaio charpy $\mathrm{V}$ e ensaio de microdureza.

As chapas usadas foram de aço ASTM A-36 com dimensões de $280 \times 300 \mathrm{~mm}$ e espessura de $16 \mathrm{~mm}$ preparadas com chanfro $\mathrm{V}$ de $60^{\circ}$. Os eletrodos oxi-rutílicos foram produzidos pela ESAB. Sua alma é de um aço baixo carbono, com diâmetro de $3.25 \mathrm{~mm}$ e comprimento de $35 \mathrm{~mm}$. A composição química do metal de solda é apresentada na tabela 1.

\subsection{Métodos:}

A soldagem foi realizada no laboratório de soldagem da Universidade Federal de Minas Gerais (UFMG). Para a

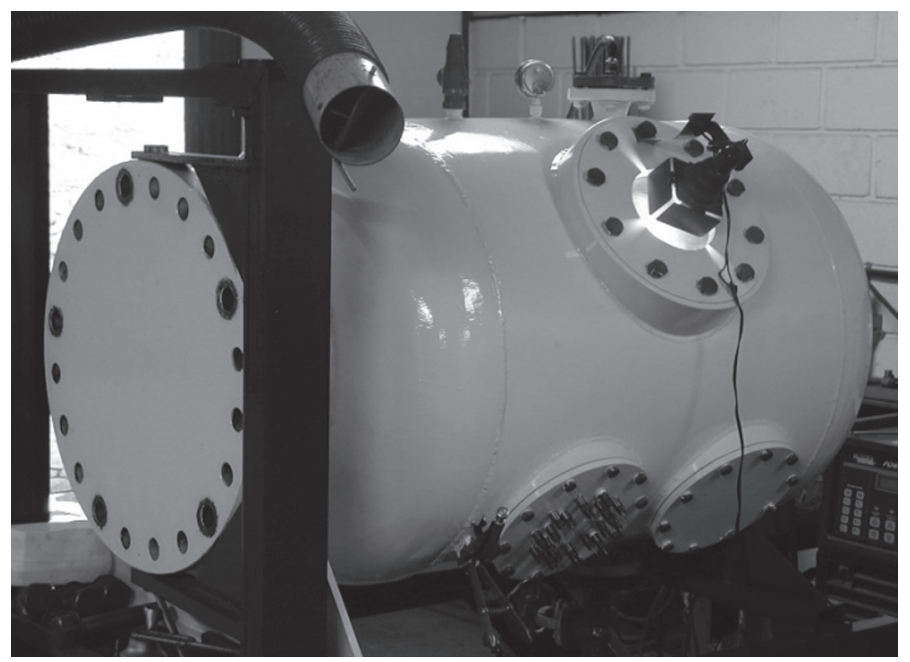

Figura 1: Sistema de soldagem por gravidade. (b) Simulador de soldagem hiperbárica empregado nos testes de soldagem a $10 \mathrm{~m}$ e $20 \mathrm{~m}$ de profundidade equivalente 
realização deste processo foi utilizada uma fonte de soldagem eletrônica - LINCOLN ELETRIC, modelo POWER WAVE 450. Para simular a profundidade de $10 \mathrm{~m}$ foi utilizado um simulador de soldagem hiperbárica, como mostra a Figura 1, que permite trabalhar com pressões de até $20 \mathrm{~atm}$.

As soldas foram realizadas em água doce, por arraste, na posição plana, em polaridade direta, com inclinação do eletrodo de $60^{\circ}$ e corrente na faixa de 150 a $170 \mathrm{~A}$. O dispositivo de soldagem por gravidade inserido dentro do simulador hiperbárico para realização das soldas.

Com isso, foram produzidas três placas soldadas pelos eletrodos B, C e D. Em seguida, estas placas foram usinadas no laboratório do Instituto de Tecnologia PUC-Rio (ITUC), para a produção dos corpos de prova. De cada placa soldada foram retirados os seguintes corpos de prova:

- Três amostras para macro e micrografia,

- Uma amostra para o ensaio Charpy V,

- Uma amostra para o ensaio de tração.

Para as amostras A e E (já usinadas anteriormente) havia três corpos de prova com as seguintes especificidades:

- Duas amostras de A e duas mostras de E para macro e micrografia,

- Uma amostra $(0 \% \mathrm{Mo})$ para o ensaio de tração.

Somando, ao todo, vinte amostras utilizadas neste trabalho. Em seguida estes copos de prova foram submetidos ao ensaio metalográfico realizados no Laboratório de Metalografia e Tratamentos Térmicos (LMTT) PUC-Rio.

$\mathrm{Na}$ caracterização microestrutural por microscopia ótica, a metodologia aplicada para a análise das microestruturas, das regiões presentes no metal de solda e a medição do tamanho de grão foi na elaboração de mosaicos, que são estruturas compostas por vários campos de imagens concatenadas nas direções $\mathrm{x} e$ y através do deslocamento motorizado da amostra, formando uma única imagem que cobre grandes regiões das amostras nas quais as estruturas relevantes são maiores do que o campo a uma

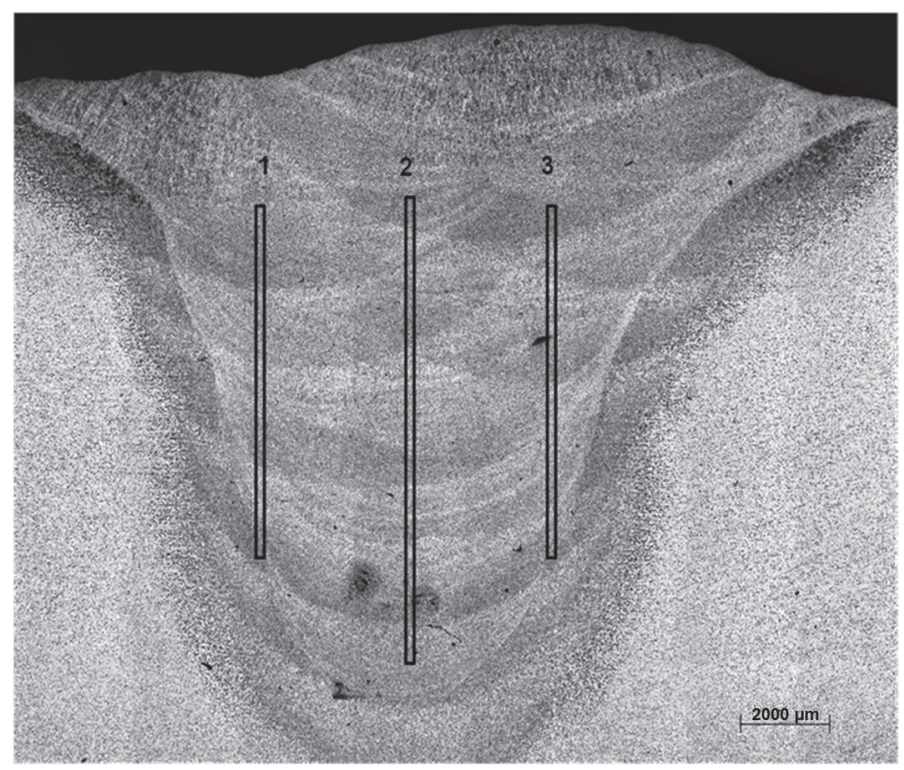

Figura 2: Mosaico da amostra. Aumento de 50x dada magnificação. Primeiro foi feito um mosaico (aumento de 50x) de toda a face polida da amostra, com a finalidade de servir de base de marcação espacial para a elaboração dos próximos mosaicos. Os mosaicos nomeados por 1, 2 e 3 são compostos de aproximadamente cinquenta e três imagens (cerca de $10 \mathrm{~mm}$ de comprimento), sendo estas imagens posicionadas uma embaixo da outra, formando uma única coluna (Figura 2). Os ensaios mecânicos realizados foram os de dureza (HV5), Charpy V $\left(0^{\circ} \mathrm{C}\right)$ e tração. Dos resultados obtidos foram feitas médias e desvios padrão que possibilitaram avaliar as propriedades mecânicas do metal de solda. Para a análise química, a técnica aplicada foi a de espectroscopia de emissão ótica, realizada pela FUNSHEL (Fundição Artística e Industrial LTDA).

\section{Resultados e Discussão}

Pela análise quantitativa dos resultados de composição química do metal de solda apresentados na Tabela 1, constatase que os eletrodos testados no presente trabalho comportamse como eletrodos do tipo oxidante. Isto está evidenciado pelos baixos teores de $\mathrm{Mn}$ e Si obtidos. Coerentemente o teor de oxigênio do metal de solda é elevado (tipicamente $0.268 \%$ para o eletrodo A) e o teor de carbono é bem inferior ao comumente observado nos metais de solda de aços ferríticos. É possível também observar que o teor de molibdênio é crescente e o teor de níquel manteve-se razoavelmente estável, como o previsto.

As análises realizadas por microscopia ótica (MO) das microestruturas (\% em peso) presentes no metal de solda estão apresentadas na Tabela 2. Os resultados mostram que o percentual de FSF-A, FSF-NA e FA, localizados na região colunar e na região de grãos grosseiros são baixos mesmo contendo em sua composição química os elementos Mo e Ni, que são ativadores da formação destes microconstituintes. Este pequeno percentual se justifica pelo fato do metal de solda conter baixo teor de carbono. Como consequência benéfica da adição de Mo obtevese ainda a formação de ferrita acicular na região reaquecida (FAR). Os resultados apresentados mostram que pequenas adições de Mo (eletrodo B) aumentam consideravelmente a quantidade deste constituinte. Sua morfologia assemelha-se com a ferrita acicular encontrada na região colunar e na região de grãos grosseiros. Também é possível observar que existe um aumento percentual de agregado ferrita-carbeto (AFC) com o aumento de Mo. Estes microconstituintes são mostrados na Figura 3.

Os resultados das análises de fração de área dos $\mathrm{AFC}$ mostraram que os valores deste micro-constituinte aumentam com o aumento do teor de Mo no metal de solda (Tabela 2) coerentemente com a tendência à formação de carbetos, característica do Mo. A Figura 5 mostra a influência do Mo sobre formação de AFC. Os valores encontrados de AFC combinados com o refino de grãos indicam influencia significativa nas propriedades mecânicas do metal de solda. Os valores de dureza apresentados pelas amostras que contêm molibdênio mostraram que a adição deste elemento aumenta a dureza do metal de solda (Tabela 1). A Figura 6 mostra o aumento da fração de área dos AFC juntamente com o aumento da dureza do metal de solda.

Os resultados obtidos pela análise (MO) das regiões presentes 
Tabela 1: Composição química do metal de solda (porcentagem em peso)

\begin{tabular}{|c|c|c|c|c|c|c|c|c|c|}
\hline Eletrodo & $\mathrm{C}$ & $\mathrm{Si}$ & $\mathrm{P}$ & $\mathrm{S}$ & $\mathrm{Mn}$ & $\mathrm{Mo}$ & $\mathrm{Ni}$ & $\mathrm{Cu}$ & $\mathrm{O}$ \\
\hline $\mathrm{A}$ & 0.052 & 0.009 & 0.025 & 0.008 & 0.048 & 0.003 & 2.08 & 0.035 & 0.268 \\
\hline $\mathrm{B}$ & 0.027 & 0.014 & 0.027 & 0.011 & 0.051 & 0.099 & 1.98 & 0.077 & $*$ \\
\hline $\mathrm{C}$ & 0.031 & 0.009 & 0.028 & 0.011 & 0.047 & 0.125 & 2.17 & 0.080 & $*$ \\
\hline $\mathrm{D}$ & 0.027 & 0.015 & 0.030 & 0.012 & 0.051 & 0.250 & 2.00 & 0.076 & $*$ \\
\hline $\mathrm{E}$ & 0.051 & 0.017 & 0.032 & 0.008 & 0.069 & 0.396 & 2.10 & 0.038 & $*$ \\
\hline
\end{tabular}

Tabela 2: Fração de micro-constituintes do metal de solda (porcentagem em área)

\begin{tabular}{|c|c|c|c|c|c|c|c|}
\hline Eletrodo & FPE & FSF-A & FSF-NA & FA & FP & FA-R & AFC \\
\hline A & 6.11 & 2.03 & 0.01 & 0.72 & 90.5 & 0.23 & 0.40 \\
\hline B & 1.32 & 5.88 & 0.06 & 0.26 & 86.9 & 3.34 & 2.25 \\
\hline C & 4.20 & 2.42 & 0.16 & 0.97 & 74.5 & 15.2 & 2.50 \\
\hline D & 0.57 & 0.18 & 0.07 & 0.14 & 90.9 & 5.14 & 3.02 \\
\hline E & 9.98 & 5.05 & 0.11 & 0.61 & 74.2 & 6.05 & 3.95 \\
\hline
\end{tabular}

* FPE: ferrita pró-eutetóide, FSF-A: ferrita com segundas fases alinhadas, FSF-NA: ferrita com segundas fases não alinhadas, FA: ferrita acicular, FP: ferrita poligonal, FA-R: ferrita acicular na região reaquecida, AFC: agregado ferrita-carbeto.

Tabela 3: Fração de área das regiões (\% em área)

\begin{tabular}{|c|c|c|c|}
\hline Eletrodos & RC & RGG & RGF \\
\hline $\mathrm{A}$ & 4.0 & 20 & 76 \\
\hline $\mathrm{B}$ & 7.7 & 17.3 & 75 \\
\hline $\mathrm{C}$ & 6.0 & 12.7 & 81.3 \\
\hline $\mathrm{D}$ & 13.3 & 8.0 & 78.7 \\
\hline $\mathrm{E}$ & 9.0 & 15 & 76 \\
\hline
\end{tabular}

* RC: região colunar, RGG: região reaquecida de grãos grosseiros, RGF: região reaquecida de grãos finos

no metal solda (Tabela 3) mostram que a maior parte do metal de solda (da ordem de $75 \%$ a $80 \%$ ), para todos os eletrodos, é formada pela região de grãos finos (RGF). Tanto a região colunar quanto a região reaquecida de grãos grosseiros apresentaram frações de área bem pequenas. Isto evidencia que na RGF, devem ser concentrados os maiores esforços para melhorar as propriedades mecânicas do metal de solda. O tamanho de grão da RGF foi reduzido com a adição de molibdênio. A Figura 4 mostra claramente que a adição de $0.099 \%$ de Mo (eletrodo B) diminui razoavelmente o tamanho médio de grão. Após esta queda o tamanho de grão permanece praticamente constante para os crescentes teores de Mo. 

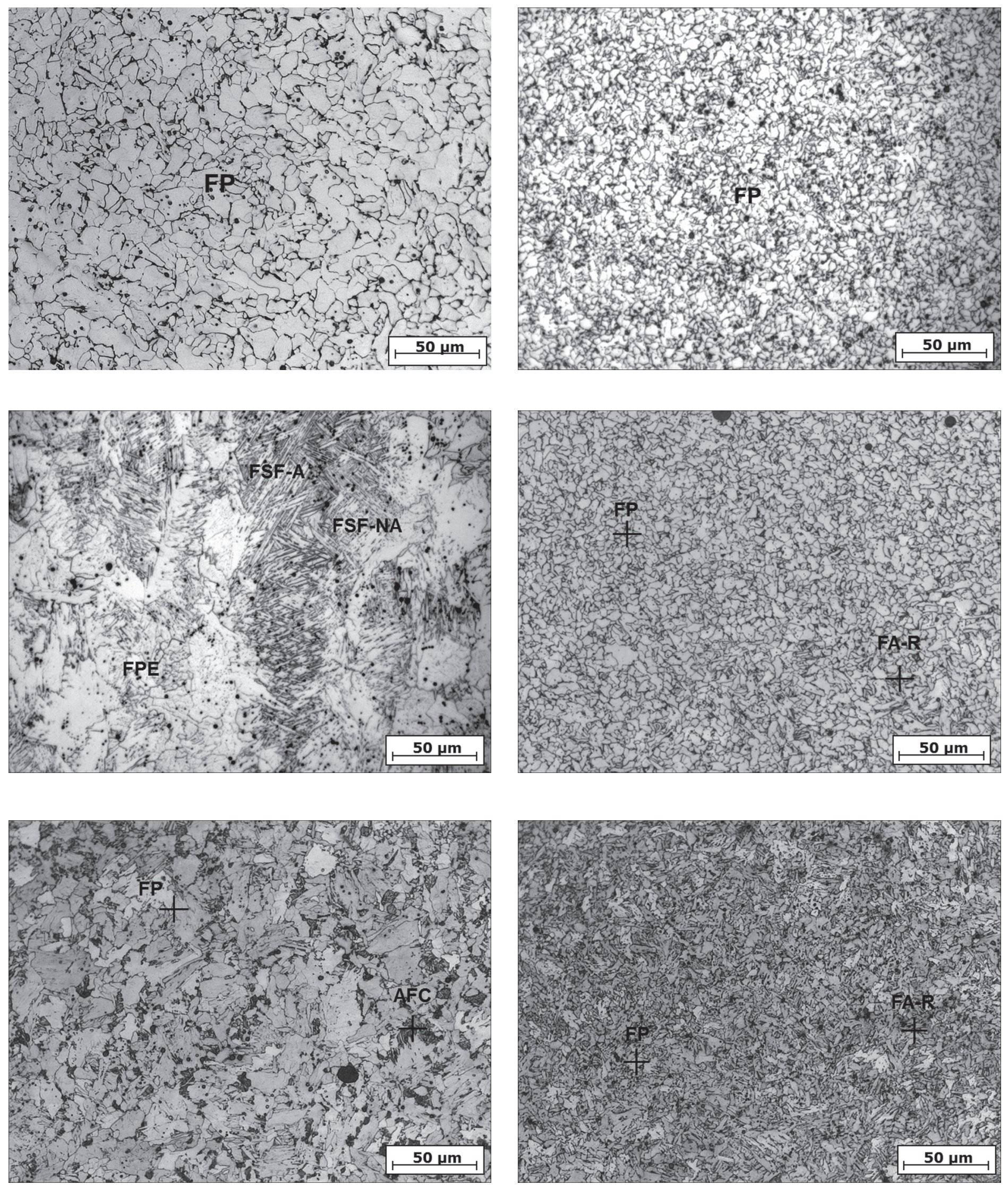

Figura 3: Micro-estruturas presentes no metal de solda, (a) eletrodo A, (b) eletrodo C, (c) eletrodo D, (d) eletrodo D, (e) eletrodo E e (f) eletrodo E 


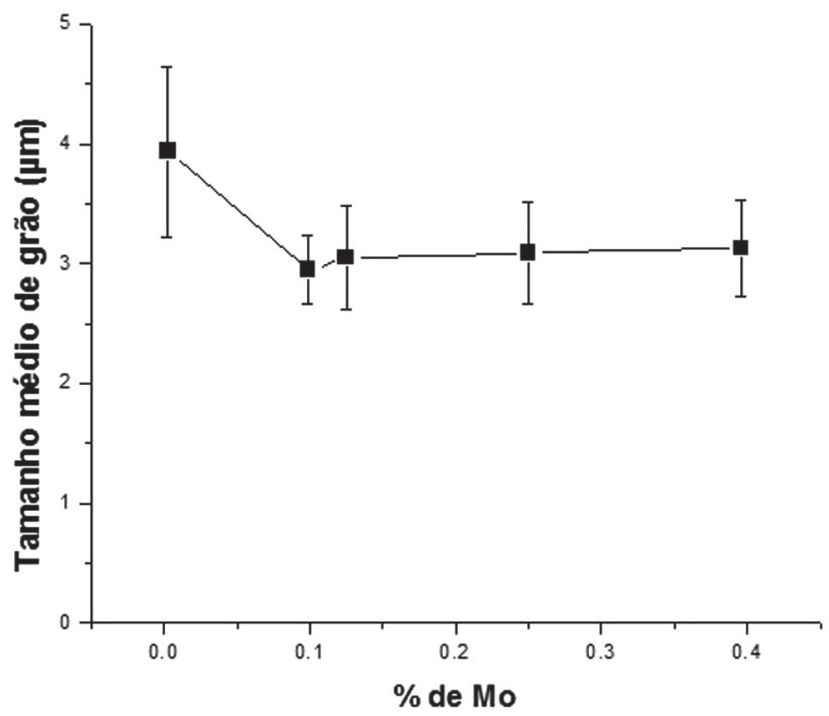

Figura 4: Tamanho médio de grão versus teor de Mo

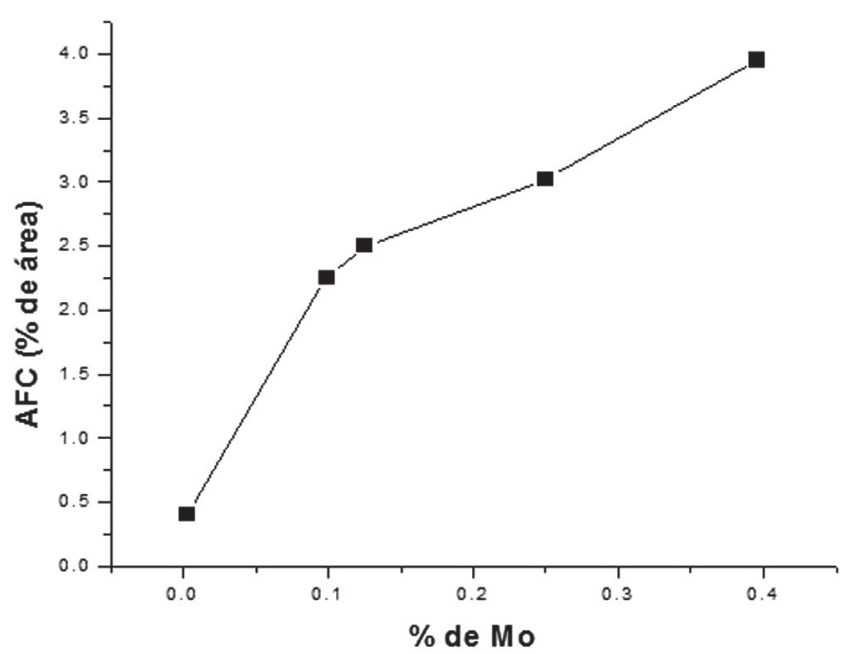

Figura 5: Relação entre o teor de Mo e quantidade relativa de $\mathrm{AFC}$

Os resultados dos ensaios mecânicos estão apresentados na Tabela 4. A justificativa para a o bom valor de tenacidade do

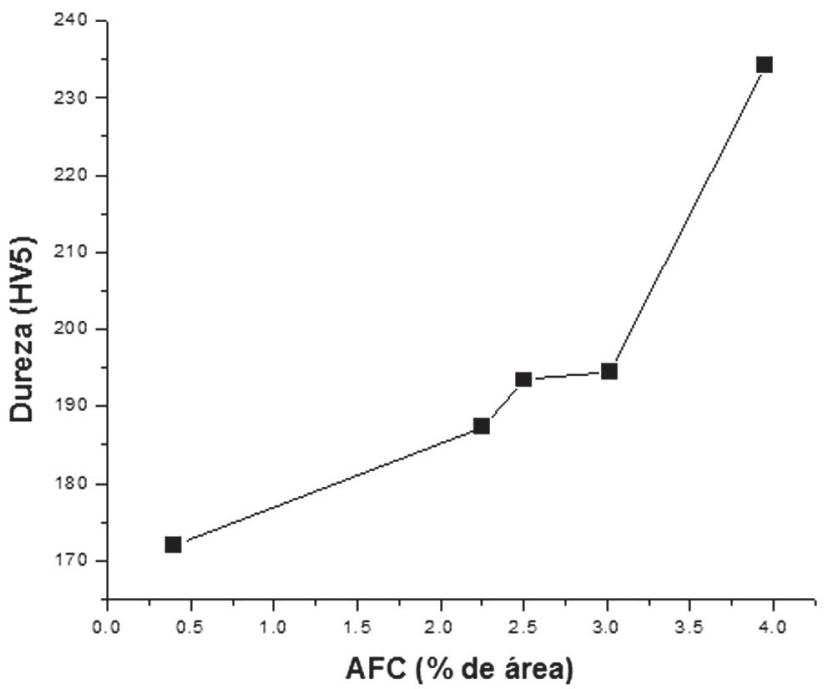

Figura 6: Relação entre a dureza e AFC

metal de solda é dada pela microestrutura de FP e o tamanho bem pequeno destes grãos localizados na região reaquecida de grãos finos, como pode ser visto pelo eletrodo $\mathrm{C}$ que contém a maior fração de RGF ( $81.3 \%$ de área) e que também apresentou o maior valor de energia charpy, 54J (Tabela 4). A pouca fração de área da RC também contribui positivamente com a tenacidade. O eletrodo E com maior teor de Mo (0.396\%) apresenta o menor valor de energia absorvida, concluindo-se que para valores superiores ao do eletrodo D (0,25\%), o Mo influencia negativamente na tenacidade do metal de solda (fig. 7). Porém, acima deste valor o Mo influencia negativamente na tenacidade, o que atribui-se ao aumento da quantidade de AFC.

Analisando os valores percentuais de alongamento e estricção obtidos nos ensaios de tração (Tabela 4) não é possível obter qualquer conclusão sobre a influência do Mo na dutilidade do metal de solda. Estes resultados não mostram qualquer tendência. São estatisticamente pobres e foram influenciados por defeitos macroscópicos presentes nas superfícies de fratura dos corpos-de-prova.

O gráfico da Figura 8 mostra a forte influência do tamanho de grão da RGF no limite de resistência à tração. Para os três menores valores de tamanho de grão o número reduzido de

Tabela 4: Ensaios Mecânicos *

\begin{tabular}{|c|c|c|c|c|c|c|}
\hline Eletrodo & Dureza (HV5) & L.E (MPa) & L.R (MPA) & Along. (\%) & Estricção (\%) & Charpy V 0 ${ }^{\circ}$ C (J) \\
\hline A & 172 & 398 & 462 & 19 & 28.8 & 42.2 \\
\hline B & 187.4 & 410 & 483 & 27.2 & 29.4 & 11.6 \\
\hline C & 193.4 & 423 & 493 & 15.6 & 51.3 \\
\hline D & 194.4 & 434 & 496 & $*$ & $*$ \\
\hline E & 234.2 & $*$ & $*$ & $*$ & 40 \\
\hline
\end{tabular}

*Dureza: média de 5 identações, Charpy: média de 3 testes, L.E, L.R, Along, e estricção: resultados de um único ensaio. 
testes dificulta a avaliação. Entretanto, a queda abrupta no L.R. que se segue, a exemplo da tenacidade, evidencia a influência positiva do refino de grão nestes casos.

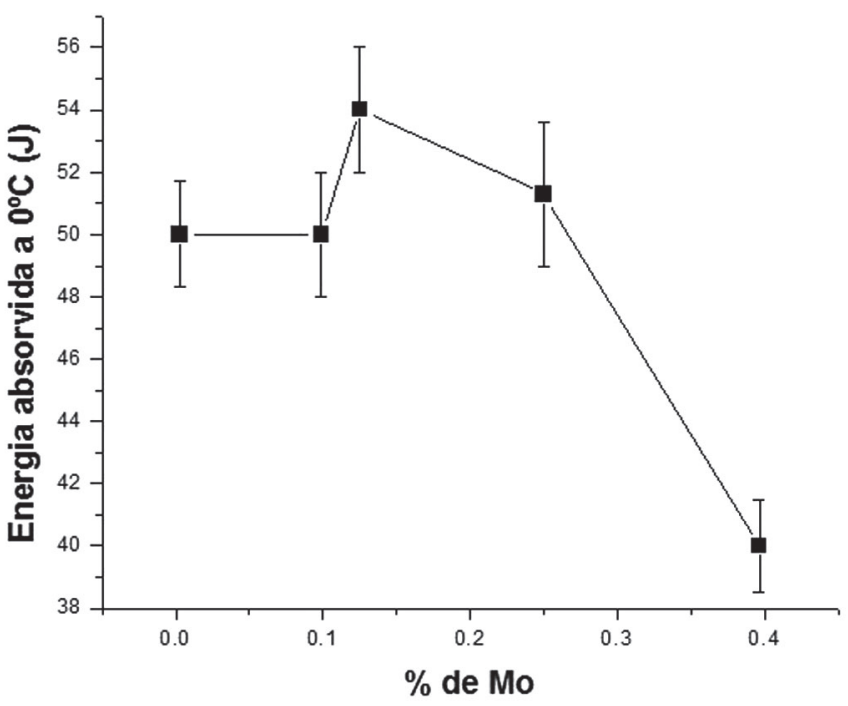

Figura 7: Teor de Mo versus energia charpy

A análise conjunta dos resultados sugere que pequenas adições de Mo (da ordem de $0,1 \%$ ) provocam todo o efeito possível nas propriedades mecânicas por refino de grão. A partir deste teor o tamanho de grão permanece constante e o mecanismo de aumento de resistência predominante passa a ser o de dispersão de segunda fase (AFC), cuja quantidade é proporcionalmente crescente em relação à dureza e ao limite de resistência à tração (Figura 9). Assim, pode-se afirmar que a adição controlada de molibdênio no metal de solda (até $0,4 \% \mathrm{Mo}$ ) traz resultados positivos para algumas das propriedades mecânicas, tais como dureza, L.E, L.R. Plotando-se dureza versus L.R observa-se com boa aproximação uma relação linear entre estas propriedades (Figura 10). Com relação à tenacidade, não se registram perdas com a adição de Mo até o valor de $0.25 \%$ Mo.

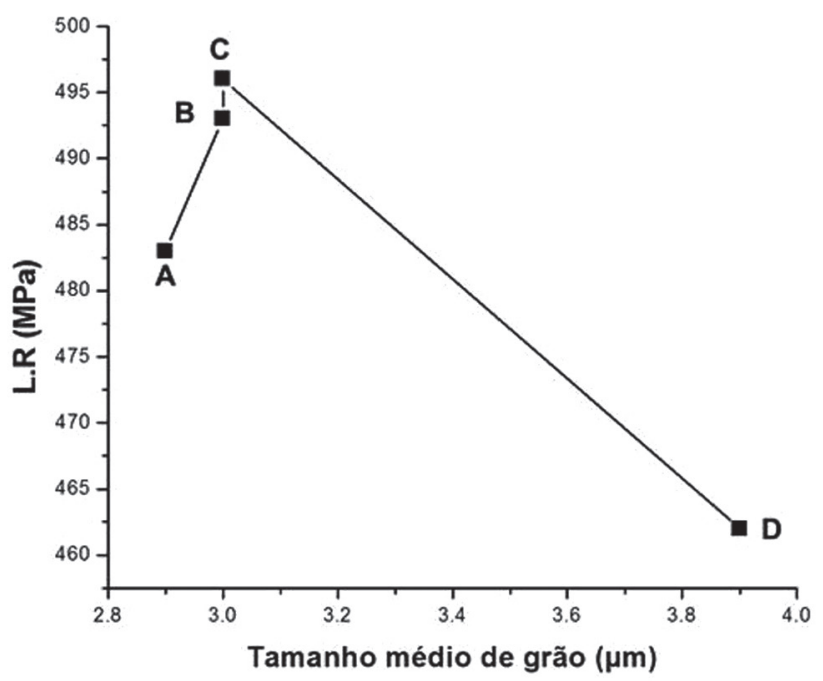

Figura 8: Relação entre o L.R e tamanho médio de grão na região na $\mathrm{RGF}$
Com base nos resultados obtidos nesta pesquisa, foi possível determinar uma faixa confiável dos teores de molibdênio para produção de eletrodos revestidos que produzam metais de solda com resistência mecânica compatível com os requisitos para qualificação na classe A da norma AWS D3.6M:1999 [1]. Esta faixa compreende de $0.099 \%$ a $0.25 \%$ em peso de Mo.

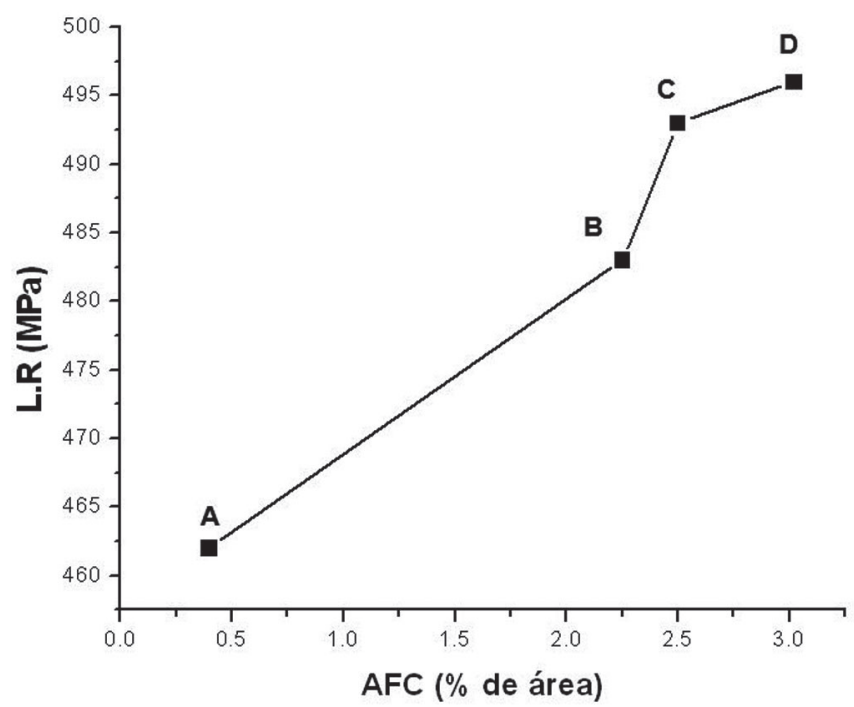

Figura 9: Relação entre o L.R e AFC

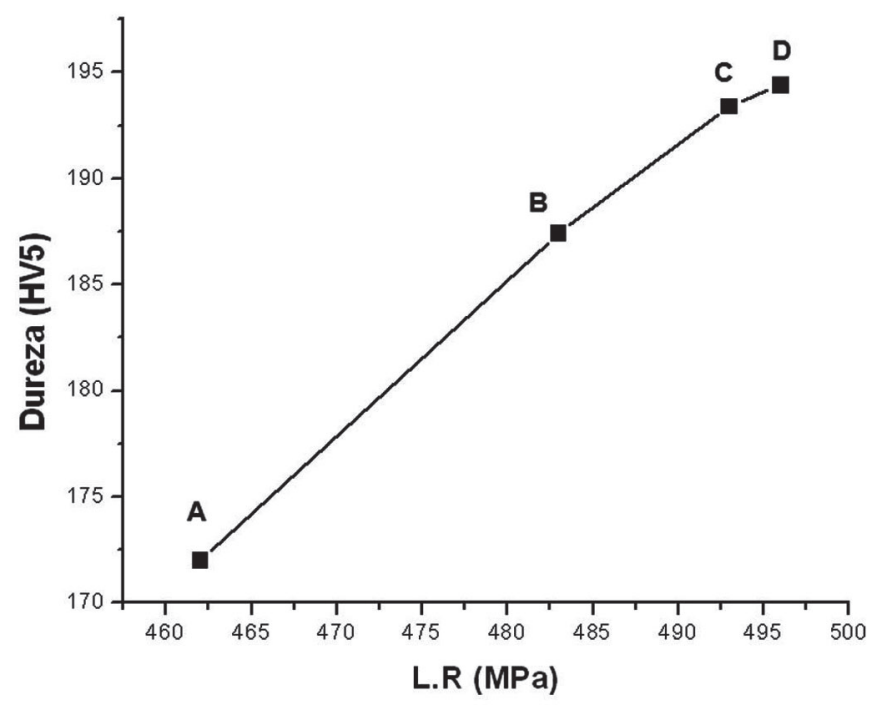

Figura 10: Relação entre a dureza e o L.R

\section{Conclusões:}

Este trabalho abrangeu a soldagem molhada a 10 metros de profundidade, realizada com eletrodos revestidos oxirutílicos com teores de $2 \% \mathrm{Ni}$ e 0 a $0.4 \%$ de Mo. O metal de solda é formado predominantemente (da ordem de $75 \%$ em área) pela região reaquecida de grãos finos e a microestrutura predominante desta região em todos os eletrodos analisados é a ferrita poligonal. Alguma presença de ferrita acicular também pode ser observada na RGF por influência da adição de Mo. 
Tanto a região colunar quanto a região reaquecida de grãos grosseiros apresentaram frações de área bem pequenas em todas as amostras analisadas.

A quantidade do micro-constituinte AFC cresce com o aumento do teor de Mo do metal de solda.

A adição de $0.099 \%$ de Mo diminui consideravelmente o tamanho de grão na RGF. Após esta queda o tamanho de grão permanece praticamente constante para os crescentes teores de Mo.

A adição de até $0.25 \%$ de Mo não mostrou influência significativa na tenacidade, mantendo os valores de energia absorvida em torno de $50 \mathrm{~J}$. Entretanto, teores acima de um valor entre $0,25 \%$ e $0,40 \%$ provocam redução da tenacidade devido à crescente quantidade de agregados ferrita-carbetos.

O L.R, o L.E e a dureza do metal de solda de todos os eletrodos aumentam continuamente com o aumento do teor de Mo. Para as menores adições propõe-se que os mecanismos de aumento de resistência predominantes são primeiramente por refino de grão e em segundo lugar por solução sólida. Em maiores adições segue-se a dispersão de segunda fase (AFC) como o mecanismo predominante.

Os resultados obtidos por esta pesquisa mostram que a faixa de 0.099 a $0.25 \%$ de Mo resulta na melhor combinação de propriedades mecânicas, podendo ser utilizada para a produção de eletrodos classe E70XX.

(Endnotes)

\section{Referências Bibliográficas:}

[1] Pessoa, E. C. P. Estudo da Variação da Porosidade ao Longo do Cordão em Soldas Subaquáticas Molhadas. Tese de Doutorado. Escola de Engenharia da UFMG. Brasil. 2007.

[2] Suga, Y. and Hasui, A. On Formation of Porosity in Underwater Weld Metal. IIW Doc. IX - 1388 - 86, April, 1986.

[3] Ibarra, S., Grubbs, C. E., and Olson, D. L. The Nature of Reactions in Underwater Welding. $19^{\text {th }}$ Annual Offshore Technology Conference Paper OTC 5388. Houston, Texas: 277281, April, 1987.

[4] Kuwana, T. and Sato, Y. Oxygen Absorption and Oxide Inclusion of Iron Weld Metal During Arc Welding. IIW Doc. IX - 1392 - 86. April, 1986.

[5] Pope, A. M. Oxygen and Hydrogen Control in Shielded Metal Underwater Wet Welding. Tese de doutorado. Colorado School of Mines. USA. 1995.

[6] Specification for Underwater Welding. American National Standard, ANSI/AWS D3.6M:1990

[7] Nóbrega, A. F. Estudo da Soldagem Subaquática Molhada com Eletrodos Revestido. Dissertação de Mestrado. Universidade Federal do Rio de Janeiro. Brasil. Agosto, 1981.

[8] Gooch, T. G. Properties of Underwater Welds. Part 2. Mechanical Properties. Metal Construction: 206-216, April, 1983b.

[9] Pope, A. M. et al., The Effect of Nickel on the Mechanical Properties of High-Oxygen Underwater Wet Weld. Journal of Offshore Mechanics and Arctic Engineering, vol. 118, p. 165168, May, 1996.
[10] Kranzlein, H. H.; Burton, M. S. and Smith G. V. Solid Solution Strengthening in Iron-Nickel and Iron-Platinum Alloys. Transactions of the Metallurgical Society of AIME; Vol 233, p. 64-70, January, USA, 1965.

[11] Evans, G. M. The Effect of Nickel on the Microestructure and Properties of C-MN All-Weld Metal Deposits. Welding Research Abroad. Vol. XXXVII, Feb-March, 1991.

[12] Trindade, V. R. et al., Influência da Adição de Níquel na Tenacidade de Metais de Solda de aços C-Mn antes e após Tratamento Térmico de Alívio de Tensões. BSoldagem e Inspeção, vol. 10, nº 10, p. 164-172, 2005.

[13] Evans, G. M. Effect of Molybdenum on Microstructure and Properties of C-Mn All-Weld Metal Deposits. Joining \& Materials, November 1988, p. 239-246.

[14] Leão, A. P. B. Adições de Cu e Mo em Metais de Solda Ligados ao Ni para Soldagem Subaquática Molhada. Dissertação de Mestrado. PUC-Rio. Brasil. 2009.

[15] Surian, E.; Ramine de Rissone, M.; De Vedia, L. Influence of Molybdenum on Ferrict High-Strangth SMAW All-WeldMetal Properties. Welding Jounal, p. 53-62, April, 2005.

[16] Bhoele, D. S. et al., Effect of Nickel and Molybdenum Addicition on Weld Metal Toughness in a Submerged Arc Welded HSLA Line-Pipe Steel. Welding Jounal, p. 53-62, April, 2005. 